\title{
Designing regulatory frameworks for merchant transmission investments by Real Options Analysis
}

\author{
Rolando Pringles $^{\mathrm{a}, \mathrm{b}, *}$, Fernando Olsina ${ }^{\mathrm{a}, \mathrm{b}}$, Francisco Garcés ${ }^{\mathrm{a}, \mathrm{b}}$ \\ ${ }^{a}$ National Scientific and Technical Research Council (CONICET) \\ ${ }^{b}$ Institute of Electrical Energy (IEE), National University of San Juan (UNSJ), \\ Av. Lib. Gral. San Martín 1109(O) J5400ARL San Juan, Argentina \\ * Corresponding author. \\ Tel.: +54-264-4226444 / Fax: +54-264-4210299/ E-Mail: rpringles@iee.unsj.edu.ar
}

\begin{abstract}
In deregulated electricity markets, the transmission network is a key infrastructure for enabling competition in the generation sector. A deficient expansion of the transmission grid prevents the realization of the benefits in terms of efficiency associated with market mechanisms. Consequently, it is essential to provide clear investment policies and economic signals to attract timely and efficient transmission investments in order to develop the system at minimum cost meeting the requirements of generators and consumers, while keeping adequate levels of service quality and reliability. This paper proposes a modern tool of economic evaluation based on Real Options Analysis that provides the regulator the ability to assess various incentives that would lead transmission investors to make efficient decisions in highly uncertain environments. Real Options properly values partially irreversible investment decisions, such as to defer, modify or abandon an investment project in response to the arrival of new information or as uncertainties are resolved. Decisions are evaluated from the point of view of a transmission investor trying to maximize its own profits in the time period set to recover the capital invested. The results allow the study of the behavior of transmission investors regarding their decision making when they have the possibility to manage the option to defer, under different regulatory schemes that encourage the expansion of the transmission system.
\end{abstract}

\section{Keywords}

Power network, planning, regulation, Real Options, uncertainty, flexibility, investment, irreversibility, Monte Carlo, simulation 


\section{Introduction}

In the last two decades, the electricity industry has faced major and significant structural and paradigmatic changes. The main objective of this restructuring has been to encourage the competition in the generation sector and provide freedom of choice for consumers in order to improve economic efficiency in delivering electricity. A crucial step has been the separation of the generation, transmission, distribution and marketing segments into autonomous businesses. The generation and marketing sectors were framed as purely competitive activities, not so the transmission and distribution sectors, which, mainly due to their still significant economies of scale, remained as regulated monopolies.

The transmission network has a vital role in competitive electricity markets because it is the central infrastructure that enables competition in the generation sector. Its main function is to provide open access without discrimination to the transmission network to both generators and consumers. It is also a vital system in the development of renewable energy as it links important remote renewable resources to consumption centers.

Given the importance of the transmission infrastructure to the objectives of competitive markets, it is imperative that the regulatory frameworks create incentives to undertake timely transmission investments that improve economic efficiency, reduce overall costs of meeting demand, preserve security of supply, promote the integration of renewable energies and encourage competition.

Under a market setting, the regulatory authorities face the need to provide incentives for technical and economic efficiency, so that the transmission system is developed at minimum cost, with adequate levels of service quality and reliability, and adapted to the requirements of generators and consumers (Wu and Wen, 2006).

In addition to the creation of stable regulatory regimes, predictable and transparent, it is necessary to combine them with a range of flexible financing tools that can address the specific risks faced by investors when evaluating projects in transmission infrastructure. Uncertainty is key factor when assessing transmission projects. Consequently, the regulatory bodies need tools for adequately evaluating investments in the transmission system under conditions of high uncertainty.

Modern literature about the valuation of investments in real assets recognizes the Real Options Analysis (ROA) as an advanced tool for valuing irreversible investment projects which posse managerial flexibility in the decision making as prevailing uncertainties are (partially) resolved as new (though never complete) information arrives over time (Schwartz and Trigeorgis, 2004; Feinstein and Lander, 2002; Dixit and Pindyck, 1994). Since investment projects in the electric power transmission have indeed these characteristics, the potential of Real Option Analysis can be fully exploited. 
This paper proposes the implementation of a modern tool of economic evaluation based on ROA that allows the regulatory body to analyze various mechanisms to efficiently encourage investment projects in power transmission capacity. Real Options Analysis enables the regulatory authority to analyze investor behavior with respect to decision-making in terms of cost and the duration of the construction license; the impact of recognizing a premium on cost of capital upon the investment decision; the appropriate level of regulated returns that encourages private investment; and the implications of introducing maximum market prices (price-caps) on investor behavior in transmission. This analysis serves for determining the parameters value of the regulatory framework design for merchant transmission in order to provide efficient and timely signals to promote expansion of the power network infrastructure.

This reminder of this article is organized as follows. Section 2 reviews the difficulties of traditional methods to assess irreversible investments under uncertainty and managerial flexibility and provides the fundamentals of Real Option Analysis. A simulation-based method for valuing Real Option in the context of power transmission investments is described in Section 3. Regulatory incentives for transmission system expansion under merchant transmission scheme are quantitatively assessed in Section 4. Besides, detailed results about the value of the option to defer the transmission investment as a function of regulatory actions are illustrated and discussed. Conclusions and policy recommendations are provided in Section 5.

\section{Background}

\subsection{Valuation of flexible investments under uncertainty}

Among the traditional methods for assessing investment, the net present value of discounted cash flows (NPV) is perhaps the most widely appraisal tool spread among practitioners, companies and decision makers. However this approach is not exempt of important drawbacks. In addition to the problem of forecasting and discounting future cash flows, the main disadvantage of NPVbased methods is that they cannot adequately address the issue of flexibility in decision-making under uncertain future circumstances.

The NPV decision rule prescribes to undertake investments with positive net present values and, otherwise reject them. However, with this immediate acceptance/rejection decision, the NPV implicitly ignores the value of the real options typically embedded in capital investment projects, such as the option to postpone an investment, the option to expand or contract the installed capacity, the option to close a business, or the option of abandoning the project for a salvage value, according to unfolding future circumstances. When market conditions are highly uncertain, flexibility options present in projects can add significant value and become attractive. In a context of considerable uncertainty, it is demonstrated that the NPV approach substantially underestimates the value of capital investments leading to inefficient or plainly wrong decisions 
(Keswani and Shackleton, 2006; Schwartz and Trigeorgis, 2004; Feinstein and Lander, 2002; Dixit and Pindyck, 1994).

Unlike the NPV approach, Real Options Analysis can properly account for the economic value of having the flexibility to change or revise decisions later when the uncertainty around critical variables is resolved. As is shown in Miller and Park (2002), while the analysis of discounted cash flows is applicable only to projects with low-volatility returns or now-or never investment opportunities, ROA is applicable to most projects because of its effectiveness to manage the high volatility that characterizes investment projects under real conditions. The growing list of uses of ROA includes R\&D industries (e.g. pharmaceuticals), technology investments, natural resource industries (oil, mining and forestry), manufacturing and stock projects (see Miller and Park (2002) and Trigeorgis (1996) for more details and references).

\subsection{Real Options Analysis}

The analysis of Real Options represent a conceptual extension of financial option theory (Black and Scholes, 1973) applied to tangible or real assets. A financial option gives its owner the right, but not the obligation, to buy or sell a financial asset at a specified price. Similarly, a firm that makes strategic investments has the right, but not the obligation, to take advantage of these opportunities to obtain a profit in the future. A strategic investment opportunity may be considered as a source of cash flows plus a series of options or contingent decisions. The Real Options approach, like financial options, provides the holder the right to protect against losses without limiting its earnings.

Real Options Analysis helps executives to study from a new perspective the opportunities to plan and manage strategic investments (Myers, 1984). Real Options can be present in plans, projects or flexible business investments. These options may be to postpone, expand, contract or even abandon the investment projects. Other types of Real Options can be to change the use, modify the technology or extend the lifetime of the project. Some options occur naturally. Others may be deliberately planned or built at a determined cost.

The presence of Real Options increases the value of an investment project. The value of a project with flexibility is determined as the value of the project without options, classically calculated using the traditional NPV, plus the monetary value of the flexibility provided by the managerial options:

$N P V_{\text {flexible }}=N P V_{\text {classic }}+$ Value of Real Options

As the value of the options (flexibility) is always positive, the inequality $N P V_{\text {flexible }} \geq N P V_{\text {classic }}$ holds. 
The potential of the Real Options methodology is reflected in the valuation of investment projects in which the following conditions holds: the investment project is partially or completely irreversible, there is uncertainty about the future performance of the investment, the management has some flexibility regarding the opportunity for effectively carrying out the investment, and it is possible to acquire new information about the future evolution of a relevant variable, although this information may be incomplete.

\section{Methodology}

\subsection{Evaluation of investments in transmission capacity with Real Options}

In the last decade, Real Options Analysis has seen an important development in the field of electricity markets. The introduction of competitive markets and the large number of participating agents dramatically increased the uncertainty about key market variables. The main reason for the increase of uncertainty is the decentralization of decision-making, the competitive strategies of the agents and regulatory frameworks that often require periodical adjustments.

Most applications of ROA are concentrated in the generation sector, mainly oriented to the valuation of investments on different generation technologies and fuel types. The implementation and development of ROA in the power transmission sector has been very limited, focusing on general concepts and with few specific applications to real problems (Pringles et al., 2007). In recent years the importance of this technique has been shown and some important progress has been achieved (Blanco et al., 2011; Vazquez and Olsina, 2007; Wijnia, 2005).

The valuation of Real Options embedded in the expansion investments of the transmission system has important and particular characteristics. As a consequence not all Real Options valuation methods are appropriate for appraising these types of investments. Transmission investments are American-type options (which can be exercised at any point in time during their lifetime), the decisions have a path-dependent nature and the value of the underlying assets has multiple sources of uncertainty.

Investments with the above characteristics cannot be properly evaluated by the traditional methods developed for financial options, such as the Black-Scholes method (Black and Scholes, 1973) and binomial lattices (Cox et al., 1979), as theoretical conditions for applying these approaches are typically not satisfied in transmission investment projects. Consequently, recent research and developments in computational finance have focused on numerical simulation methods for valuating complex options with multiple uncertain variables and path-dependent features.

A stochastic simulation method called Least Squares Monte Carlo (LSMC) developed by Longstaff and Schwartz (2001) has been proposed in the field of computational finance to appraise American-type options. The LSMC method combines Monte Carlo simulations with 
stochastic dynamic programming. The continuation function of the Bellman equation is estimated by means of least squares linear regression techniques. The estimated continuation value is an unbiased and efficient estimator of the conditional expectation function. By estimating the continuation function, the optimal exercise rule for the option can be found without exhaustively evaluating the state space.

The option valuation method through LSMC presents a great potential for assessing investments in electric power transmission under a market environment. Indeed, the LSMC simulation method properly evaluate American type options; it incorporates a direct treatment of all types of assets; the value of the underlying asset does not need to have a log-normal probability distribution; it can take into account many sources of uncertainties with different types of stochastic behavior; it does not require that the returns of the underlying asset have a constant variance; and the dimensionality problem that characterizes conventional stochastic dynamic programming algorithms is circumvented.

Another important property the LSMC method is its suitability to the application of distributed computing techniques, which dramatically accelerate calculation times. This is a very important feature when evaluating investments in the transmission system. In fact, in order to obtain the annual revenues of a transmission project it is necessary, for each level of demand and operating state of the system, to determine the locational marginal prices (LMP) at each system node during the time horizon, typically a decade or more. Indeed, without the aid of distributed computing techniques, the valuation of investments in the transmission infrastructure would be impractical or infeasible with current computer technology.

\subsection{Valuation of the deferral option}

The option to defer corresponds to a simple American-type option, i.e., the holder has the right to exercise the option to invest at any time until the expiration date, to the extent that the driving uncertainties are unveiled.

The value of an American option that has not yet been exercised at time $t$ is given by the following expression:

$$
F(t)=\max _{\tau \in \Upsilon(t, T)}\left\{\mathbb{E}_{Q}\left[(1+r) e^{-(\tau-t)} \Pi\left(\tau, X_{\tau}\right)\right]\right\}
$$

where $\Upsilon(t, T)$ is the set of optimal exercise times in the interval $[t, T], T$ being the expiration date of the option. $\mathbb{E}_{Q}[\cdot]$ represents the risk-neutral expected value operator, conditional to the information set available at $t$, and $\Pi\left(\tau, X_{\tau}\right)$ is the revenue function of the option at the time instant $\tau$. 
The LSMC evaluation method provides an approximate path for the optimal stopping rule that maximizes the value of the American option. It is considered that the options may be exercised in $N$ discrete times $0 \leq t_{1} \leq \ldots \leq t_{N}=T$, where $T$ is the expiration date of the option. The value of the option can be approximated considering a large enough $N$.

The evaluation begins by generating a number of paths $w$, which simulate the stochastic dynamics of each of the state variables $X_{t}$, that affect the value of the option. The aim of LSMC is to provide an exercise rule that maximizes the value of the option at each time step along each simulated path. The evaluation begins at the expiration date and continues recursively until the instant $t=0$.

The value of the underlying asset is compared with the value of exercising the option on the expiration date. The optimal exercise strategy for the postponement option, similar to a financial option to buy (call option), is to exercise the option if the value of the underlying asset is greater than the strike price; in this case it is said that the option is in the money. When the value of the underlying asset is lower than the value of exercising the option, it is allowed to expire without being exercised. In this case, it is said that the option is out of the money. The option value is therefore given by the classical formula:

$$
F(T, w)=\max [S(T, w)-K, 0]
$$

where $F(T, w)$ represents the value of the option to defer at the instant $T$ for the path $w$; the price of the underlying asset $S(T, w)$ is the expected cash flow generated by the project minus the value of the cash flow which has been renounced, $\left(I_{N}-I_{R}\right)$, and the exercise price $K$ is the difference in the cost of executing the project between the instant of time $t=T$ and $t=0$, $\left(C_{I}-C_{I_{0}}\right)$, which gives the value of the option as:

$F(T, w)=\max \left[\left(I_{N}-I_{R}\right)-\left(C_{I}-C_{I_{0}}\right) ; 0\right]$

where $I_{N}$ is the present value of the income obtained from the moment the project is executed $t=T . I_{R}$ is the present value of the renounced income supposing the project had been executed at the instant $t=0 . C_{I}$ represents the cost of the investment at the time instant $T$ and $C_{I_{0}}$ is the present value of the cost incurred at $t=0$.

Over an instant of time $t_{i}$, where $t_{i}$ is the $i$-th instant before the expiration date, the optimal strategy results from comparing the immediate exercise value (the cash flows that exercising the option would generate) with the expected cash flows from continuing, i.e. keeping the option alive. In this case, the optimal decision is to exercise if the immediate exercise value is positive and greater than the conditional expected value of continuing: 
$F\left(t_{i}, w\right)=\max \left[S\left(t_{i}, w\right)-K, \Phi\left(t_{i}, w\right)\right]$

The theory of arbitrage-free valuation implies that the value of continuing, or equivalently, the value of the option, assuming it has not been exercised before the instant of time $t_{i}$, is given by the expectation of the cash flows generated by the option $\Pi\left(\tau, t_{i+1}, T, w\right)$ discounted with respect to a measure of risk-free valuation $Q, r$ being the risk-free discount rate on which the owner follows the optimal stopping strategy for every $\tau$, with $t_{i+1} \leq \tau \leq T$.

$\Phi\left(t_{i}, w\right)=(1+r)^{-\left(t_{i+1}-t_{i}\right)} \mathbb{E} Q\left[\Pi\left(\tau, t_{i+1}, T, w\right)\right]$

The value of the option is maximized along the path if the investor exercises it as soon as the immediate exercise value is greater than or equal to the value of continuing. Thus, the key to optimally exercising an American style option is to estimate the value of continuing, this being the main difficult of the method.

The LSMC approach uses least squares regression techniques to approximate the conditional expectation function at each of the time instant $t$, which are represented as a linear combinations of subsets of orthonormal basis functions $\{L\}$ :

$\Phi\left(t, X_{t}\right)=\sum_{m=1}^{\infty} \varphi_{m}(t) \cdot L_{m}\left(t, X_{m}\right)$

Generally, the functions used are Hermite functions, Legendre, Chebyshev, Jacobi polynomials, Fourier series, polynomial powers, among others (Longstaff and Schwartz, 2001).

The values of $\varphi_{m}$ are estimated by least-square regression of $\Phi_{M}\left(t, X_{t}\right)$ with $M$ elements of the selected base functions and $M<\infty$.

$\left\{\hat{\varphi}\left(t_{i}\right)\right\}_{m=1}^{M}=\arg \min _{\left\{\varphi_{m=1}^{M}\right\}}\left\|\sum_{m=1}^{M} \varphi_{m}\left(t_{i}\right) \cdot L_{m}\left(t_{i}, X_{t_{i}}\right)-\sum_{j=i+1}^{N}(1+r)^{-\left(t_{j}-t_{i}\right)} F\left(j, t_{i+1}, T, \cdot\right)\right\|$

Where $\|\cdot\|$ is the norm of the Hilbert vector space, $M<\infty$ from which the estimated value of the continuation function results:

$\hat{\Phi}_{M}\left(t_{i}, X_{t_{i}}\right)=\sum_{m=1}^{M} \hat{\varphi}_{m}\left(t_{i}\right) \cdot L_{m}\left(t_{i}, X_{t_{i}}\right)$ 
To determine the estimated value of the continuation function, $\hat{\Phi}_{M}\left(t_{i}, X_{t_{i}}\right)$, only the paths that are in the money are considered, as the decision to exercise is only relevant for this condition. In this way, we restrict ourselves to the region over which the conditional expectation must be estimated, which reduces the number of base functions needed to obtain a good approximation of the continuation function.

Once $\hat{\Phi}_{M}\left(t_{i}, X_{t_{i}}\right)$ is estimated for the instant $t_{i}$, we can determine whether the exercise of the option is optimal or not. Then, the optimal exercise moment $\tau(w)$ at each instant of time $t$ occurs if the condition $\left[\mathrm{VP}\left(t_{i}, w\right)\right] \geq \hat{\Phi}_{M}\left(t_{i}, X_{t_{i}}\right)$ is satisfied.

As soon as the exercise decision is identified for time $t_{i}$, it is possible to determine the path of the cash flows of the option for the instant $t_{i-1}$. In this way, the recursive process continues backward, repeating the procedure until the exercise decisions are determined for each exercise time along each path. This recursive procedure determines the optimal exercise boundary for each one of the $w$ paths simulated.

Finally, the estimated value of the options is computed by discounting the cash flow resulting from the optimal exercise of the options back to the instant $t=0$, at the risk-free rate and taking the average over all $w$ sample paths:

$$
F(0)=\frac{1}{W} \sum_{w=1}^{W}(1+r)^{\tau(w)} F(\tau, w)
$$

\subsection{Regulatory incentives to the expansion of the transmission system}

The aim of regulating the transmission business is to provide a normative framework guiding towards efficient and timely expansion of the transmission network, adapted to current and future needs of the power system and according to some specified reliability criteria.

After more than two decades of having competitive markets in the electricity sector, there is still much debate about the most efficient way to attract timely investments towards the efficient development of the transmission network.

Two rather opposite approaches have emerged as incentive mechanisms to develop the expansion of the transmission system. The first is a fully regulated mechanism where the regulatory agency sets the desired expansion project and establishes the compensation rules for the transmission service. Under this scheme, the risk of bad decisions is put on consumers. The second mechanism relies on price signals and expectations of profitability for guiding investors 
in the necessity of new transmission. This scheme is often referred as merchant transmission and risk of wrong investment decisions are fully beared by the transmission incumbents.

Various international experiences show that the models based on regulated investments do not generate sufficient incentives for the expansion of the transmission system. On the other hand, mechanisms base on locational marginal pricing do not compensate all transmission costs (Joskow and Tirole, 2005; Rosellón; 2003; Perez-Arriaga et al., 1995).

With the aim of overcoming the limitations of current methods, hybrid methods that combine the features of regulated and market approaches and that provide incentives for an efficient expansion of the transmission system are being investigated. Recently, some regulatory schemes, that mix elements of the regulated and the merchant approach, have been proposed (Hogan et al., 2010, Blanco et al., 2009, Littlechild, 2003).

For recovering investments, a hybrid regulatory approach from a market remuneration scheme combined with a mechanism of complementary charges can be structured. Such an arrangement minimizes the financial risk to which investors are exposed.

Under this mechanism, the regulatory authority has a policy of active participation, as it can provide economic signals through the complementary charges that encourage investment in transmission infrastructure.

This model has desirable properties for an efficient payment of the transmission. The variable part of the income comes from the market approach and is related to the efficiency of nodal price signals, while the complementary charges seek to limit the volatility of revenues that arises from the difference between nodal prices and the allocated transmission rights, providing some hedge to market participants.

In order to establish incentives that encourage efficient and timely transmission investments, the regulatory authority must be able to properly assess the attractiveness of projects, their risks and the managerial flexibility, so as to design a regulatory framework that provides the proper economic signals for achieving a desired expansion plan.

\subsection{Assessment of regulatory incentives by Real Options Analysis}

Real Options Analysis is a modern economic valuation approach that facilitates the analysis of decision-making on transmission capacity under different types of economic and financial incentives that the regulatory authority could provide in a mixed remuneration framework.

This work proposes and evaluates a number of incentives that can be provided to merchant transmission investors under the structure of complementary charges, in addition to revenues

arising from LMP differences, in order to reduce the risk exposure and encourage a timely expansion of the transmission system: 
- Expiration time and cost of acquiring the construction license. The regulator can modify the term of the construction license in order to attract investments in transmission capacity. Additionally, the regulator can determine the appropriate value of the construction license to encourage immediate investment in transmission capacity. In this regard, it may result that the license value is negative; in this case, the investor may receive additional monetary compensation for the immediate expansion of the transmission system.

- Additional premium on the capital cost of the investment project under certain conditions of entry into the system. The aim is to encourage the early entry of strategic investments. From the consumer perspective, this is justified on the basis that the timely entry of investments generates more benefits than the premium granted to the investors. The premium over the cost of capital determined from ROA will be allocated among the transmission users through a complementary charge in the electricity tariff.

- Guaranteed returns level. The regulator can set a percentage of the value of the initial investment that investors may receive as annual additional income. This would reduce the financial risk associated to the expansion of the transmission system. The incentive encourages the transporter agent to identify the necessary expansions and to submit them to the market under a baseline scenario.

- Price caps. ROA allows the regulatory authority to determine the impact of price caps for curbing market power in the electricity market on the signal for merchant transmission investments. An adequate level of the price cap would reduce the complementary charges of the electricity tariff that are necessary to encourage investment in transmission.

\section{Results and Discussions}

In order to understand how the regulatory body can use the Real Options Analysis as a regulatory design tool we developed a simple example of investment in transmission capacity. The various actions that the regulator can consider to encourage the expansion of the transmission system are evaluated, and the economic signals that the investor ultimately perceives are analyzed and discussed in detail.

\subsection{The example case}

The considered investment project consists of an interconnection linking two electrically isolated power systems. The transmission line has a length of $350 \mathrm{~km}$ and an initial investment cost of 89.4 MUS\$. Transmission capacity of the interconnection is set equal to $1000 \mathrm{MW}$. Fig. 1 shows the topology of two power systems under analysis.

The interconnection project will be built under the mixed regulatory approach for remunerating the expansion. The transmission investor will receive market revenues as well as regulated complementary charges. 
With respect to the market structure, since the investment project is a radial line linking two autonomous systems, the investor receives long-term transmission rights (LTFTR) for a capacity equivalent to the total capacity of the transmission line. The LTFTR are awarded to the transmission investor for a period of 25 years.

The revenues of a merchant interconnection project arise from the difference in locational energy prices between both systems times the amount, in MW, of the LTFTR awarded to the owner of the transmission line. Complementary charges may be determined by the regulatory authority. Regulated revenues have duration equal to the lifetime of the allocated LTFTR. These charges help lessen the risk exposure of investors while encouraging the timely expansion of the transmission system.

For both regions, power demand is represented by a two-block load duration curve. The generation systems comprise solely thermal generating units. The generation capacity and the reliability of the generating units are represented by an equivalent generator for each system. Regardless of the aggregation of power plants for the sake of simplicity in the example, the number of system components modeled in the assessment methodology is unconstrained. Tables I, II and III provide the system data for the simulation of demand and both generation systems.

\section{$<$ Figure 1 around here $>$}

The decision on the transmission investment project is subject to the uncertainty in demand growth in both systems, generation costs and the availability of the system components. The uncertainty in demand growth in each region is modeled by a Geometric Brownian Motion (GBM) (Marathe and Ryan, 2005). The model takes into consideration the cross-correlation between the growth rates of both systems. Hourly generation costs are assumed to be a quadratic function of power delivered, i.e. marginal generation costs are linear. The uncertainty in generation costs is derived from the uncertainty in the prices of fuels consumed by the generating units. The stochastic dynamics of fuel prices is modeled by a mean reversion process with Poisson jumps (Martzoukos and Trigeorgis, 2002). As it is customary in reliability studies, the uncertainty on the operating state of system components is modeled as a two-state (OperationFailure) Markov process (Billinton and Allan, 1996), which entails that residence time of system components in both states are exponentially distributed. Table III provides the failure rate and the repair rate, $\lambda$ and $\mu$ respectively, of system components. The failure probability, denoted by $\operatorname{Pr}(\mathrm{F})$, of each component can be computed as:

$$
\operatorname{Pr}(\mathrm{F})=\frac{\lambda(t)}{\mu(t)+\lambda(t)}
$$


If system components are assumed to resided in only two mutually exclusive states, operating or failure respectively, the probability of operation $\operatorname{Pr}(\mathrm{O})$ of system components can be determined by the complementary identity $\operatorname{Pr}(\mathrm{F})+\operatorname{Pr}(\mathrm{O})=1$.

The valuation of the investment project considers that the project can be deferred. Applying Real Options Analysis, the value of the option to delay the decision to proceed, i.e. wait for better information, is analyzed under various regulatory incentives.

The cost of capital to discount the cash flows and calculate the value of traditional NPV is $12 \% / y r$. The prevailing risk-free discount rate to determine the value of the option to defer is considered as $5 \% / \mathrm{yr}$.

< Table I around here >

< Table II around here >

< Table III around here >

\subsection{Value of the option to defer the investment as a function of regulatory actions}

\subsubsection{Validity and value of the construction license}

In this Section, the impact of the expiration time and cost of the construction license issued by the authority on the financial performance of the investment project as well as on the investor behavior is assessed.

The expected net present value (NPV) of the $500 \mathrm{kV}$ interconnection line is negative and equal to \$-30.2 MUS\$. From the point of view of the transmission investor, considering only the value of the static NPV as foundation for making a decision on the investment project, as for instance it was a now-or-never opportunity, the project must be rejected.

When considering the option to defer and wait for the unfolding development of the driving market variables, it is observed that as the flexibility to postpone the investment project is higher, the option to defer increases in value. Consequently, a project having an embedded option to delay delivers a higher monetary value than an identical project without such flexibility. Fig. 2 and Fig. 3 show, respectively, the value of the option to defer and the value of the project with the option to defer embedded, as a function of the expiration time of the postponement option.

\section{$<$ Figure 2 around here $>$}

\section{$<$ Figure 3 around here $>$}


At the moment the option to defer expires, the investor loses the right to build the transmission line. In this sense, the expiration time of the option to defer is equal to the period of validity of the license to build the transmission line.

If the regulatory authority wishes to encourage immediate investment, or at least that investors acquire a construction license, they must set a minimum expiration time of the option to defer equal to or greater than three years. If the expiration time exceed this period, the value of the flexible project takes a positive value.

On the other hand, the regulatory authority should not set an exceedingly long expiration time. The value of the option to defer increases as the expiration time grows. In this sense, the investor will differ the investment project as much as possible, delaying the incorporation of the interconnection to the power system. This is one of the problems observed in the merchant approach to transmission investments. Merchant transmission projects holding long-lasting permits never materialize.

Finally, if the immediate incorporation of the transmission is required, the regulatory authority could provide an economic incentive so that the flexible NPV of the investment project is greater than or equal to zero. This incentive would be distributed among end users as a fixed complementary charge through some tariff scheme.

Regarding the value of the license, the value of the flexible NPV that exceeds the decision threshold (zero) for each expiration period of the option to defer can be taken as the maximum reference value of the construction license, with a date equivalent to the option to defer.

Figure 4 shows the value of the construction license based on the expiration date. In addition, the figure represents the economic incentive that the regulator could offer investors as a way to encourage immediate investment in the transmission system.

\section{$<$ Figure 4 around here $>$}

\subsubsection{Additional premium over the capital cost of the project}

Under certain conditions, the regulatory authority can offer the investor an additional premium to offset the cost of capital to finance the investment project. The additional premium is computed on the tariff charged to the users, but this is justified on the basis that the timely entry of investments generates higher benefits to end users than the additional costs incurred.

We present a case in which the regulatory authority considers the necessity that the investment enters in the next year. Therefore, the expiration time of the deferral option is one year and the capital cost of the investment project is $12 \%$. 
Figure 5 illustrates the value of the option to defer depending on the value of the offered premium. As the value of the premium increases, the value of the cost of capital that the investor must face decreases. Consequently, the value of the option to defer one year increases as the value of the premium recognized on the cost of capital investment increases.

The value of the flexible project considering the option to defer for several offered premium values is depicted in Fig. 6. It is observed that the value of the project increases with the increase in the premium recognized on the cost of capital. Under the market compensation approach with an additional premium of two points $(2 \%)$ on the cost of capital, the project becomes economically attractive and thus the interconnection project would actually be immediately carried out.

\section{$<$ Figure 5 around here $>$}

\section{$<$ Figure 6 around here $>$}

\subsubsection{Level of guaranteed returns}

The regulatory authority assures the investor that a percentage of the initial investment cost will be paid by end users through the electricity tariff as a fixed annuity for a period equal to the duration of the long-term transmission rights. In addition, the regulator can provide a mix between an option to defer (expiration time of the construction license) and the percentage of guaranteed return on investment. This incentive mechanism seeks to make the flexible NPV of the project greater than zero, in such a way as to attract capital investment.

On the basis of the Real Options Analysis, the regulator body can evaluate the percentage of the initial capital that it must guarantee to the investor so that the project is economically attractive, considering also the option to defer the investment, as shown in Fig. 7. In this case, we observe that as the expiration time of the option increases, the percentage of return on the initial investment that the regulator must guarantee decreases. This shows that the cost to society of postponing the entry of a system element is offset by a decrease in the fixed income that would have to be paid for the duration of the compensation of the investment project. If only about $35 \%$ of the investment cost were guaranteed by means of regulated fixed revenues, the investment should be undertaken immediately.

\section{$<$ Figure 7 around here $>$}




\subsubsection{Limit value of the energy prices}

The remuneration of a transmission project under the merchant regulatory design is a function of the locational energy price difference between the nodes interconnected by the transmission line and the capacity of the transmission rights allocated to the project. Under a situation of capacity shortfall in the importer node, i.e. there is not enough generating capacity to meet the power demand, the locational marginal price should escalate to the value of the lost load (VOLL). As the VOLL typically is very high, in many markets prices are caped below this value in order to curb market power exercised by generators. Under tight system conditions, the income of the owner of the transmission system is directly related to the value of the lost load or the ceiling price (price cap) established by the regulatory authority.

While deficit scenarios are uncommon, when they happen generate a very high extra income to investors that can thus recover much of the fixed costs of investment during these shortfall events.

Real Options Analysis is a powerful valuation tool for helping regulatory authority to analyze the behavior of transmission investments when different price cap policies are established in the marketplace.

We again evaluate a transmission investment project with the option to defer. The option has an expiration time of one year and it is assumed that the regulator desire the investment to be executed within this period. The regulated rate of return on the initial investment needed to ensure the execution of the investment based on different values of price caps are determined by the Real Options Analysis.

Figure 8 illustrates the behavior of the value of the investment project with the option to defer for one year for different values of guaranteed return rates on the initial investment when the value of price-cap is set at $\$ 1000 / \mathrm{MWh}$. It is noted that as the level of regulated returns increases, the value of the flexible project increases too, reaching a point where the project starts to be economically feasible.

Figure 9 describes the behavior of the level of return that it is necessary to guarantee to the investors so that the investment is carried out immediately according to different price-cap values. It is observed that as the value of the price cap value is set lower, the rate of the return that the regulator must guarantee to investors increases rapidly for compensating lower market revenues. If price cap is set over $4000 \$ / \mathrm{MWh}$, which is in the order to the cost of the unserved energy estimated in many systems, a guaranteed regulated return is no longer needed. This is an important finding, as it demonstrates that price caps set significantly below the VOLL, besides damaging the investment signal for new generation entry, also deteriorates the market signal for transmission expansion under the merchant regulatory design.

\section{$<$ Figure 8 around here $>$}




\section{$<$ Figure 9 around here $>$}

\section{Conclusions}

The efficient and timely expansion of transmission systems in competitive electricity markets is a problem that has not been satisfactorily resolved yet. Nowadays, many electrical supply systems face problems of congestion, market power and low security and reliability levels because of insufficient investments in transmission infrastructure.

Real Options Analysis is an advanced approach to economic valuation of irreversible investments in highly uncertain environments but with some degree of managerial flexibility. The valuation technique implemented is based on a stochastic simulation method called LeastSquares Monte Carlo. This approach has the ability to evaluate complex and compound options (American style, path-dependent), and also consider several sources of uncertainty with different stochastic dynamics.

Real Options Analysis allows the regulatory authority to quantitatively analyze various regulatory designs to encourage investment projects in power transmission capacity. We evaluated the performance of the investment as a function of cost and duration of the construction license; the impact of recognizing a premium on the cost of capital investment; the levels of regulated guaranteed returns that encourage immediate investment, and the influence of value of price caps for energy in order to provide correct signals for new infrastructure in power transmission.

Seldom transmission projects are now-or-never investments opportunities. The results of this work show that transmission projects that appropriately consider the option to defer commitment in order to get better (though never complete information) have a significantly higher economic value than the project without this flexibility.

Numeric parameters values of the regulatory design are as important as the design concept itself. The regulatory authority may adjust the minimum validity time of construction permits in order to encourage investors to acquire the license to build the interconnection. Additionally, regulators can limit the expiration date beyond this minimum validity time in order to prevent excessive delaying of the investment decision.

The result of the flexible NPV of the project sets the level of economic incentives that the investment may require for immediate exercise. Furthermore, for each expiration period of the permits, the maximum cost of the construction license can be estimated by means of Real Option valuation techniques.

When the regulatory authority can offer an additional premium to the investor that offsets a part of the cost of capital to finance the investment project, the value of the option to defer increases 
with the value of the premium recognized on the cost of investment capital. Consequently, the value of a flexible project increases as the premium increases. In this regard, the optimal level of the premium on the cost of capital that the regulatory body may offer investors to encourage timely investment in the transmission system is determined by Real Options Analysis.

In addition, Real Options Analysis enables the quantification of the percentage of the initial capital that the regulatory authority should guarantee to investors for the interconnection project to be economically attractive and executed within the expected time.

Finally, Real Options Analysis has proved useful for analyzing the detrimental impact of setting price caps in the energy market significantly below the VOLL on the transmission expansion signal.

\section{References}

Billinton, R.; Allan, R., 1996. Reliability evaluation of power systems. Plenum Press, New York.

Black, F., Scholes, M., 1973. The pricing of options and corporate liabilities. Journal of Political Economy 81(3), 637-654.

Blanco, G., Pringles, R., Olsina, F., Garcés, F., 2009. Valuing a flexible regulatory framework for transmission expansion investments. IEEE Bucharest Power Tech Conference, Jun. 28- Jul. 2, Bucharest, Rumania.

Blanco, G., Olsina, F., Garcés, F., Rehtanz, C., 2011. Real option valuation of FACTS investments based on the least square Monte Carlo method. Power Systems, IEEE Transactions on. $26(3), 1389-1398$.

Cox, J., Ross, S., Rubinstein, M., 1979. Option pricing: A simplified approach. Journal of Financial Economics 7, 229-264.

Dixit, A. C., Pindyck, R. S., 1994. Investment under uncertainty. Princeton University Press, Princeton.

Feinstein, S. P., Lander, D. M., 2002. A better understanding of why NPV undervalues managerial flexibility. The Engineering Economist 47(4), 418-435.

Hogan, W., Rosellón, J., Vogelsang, I., 2010. Toward a combined merchant-regulatory mechanism for electricity transmission expansion. Journal of Regulatory Economics 38(2), 113143.

Joskow, P., Tirole, J., 2005. Merchant transmission investment. The Journal of Industrial Economics 53(2), 233-264.

Keswani, A., Shackleton, M. B., 2006. How real option disinvestment flexibility augments project NPV. European Journal of Operational Research 168(1), 240-252. 
Littlechild, S. 2003. Transmission Regulation, Merchant Investment, and the Experience of SNI and Murray link in the Australian National Electricity Market. Mimeo, http://www.ksg.harvard.edu, 2003.

Longstaff, F. A., Schwartz, E.S., 2001. Valuing American options by simulation: A simple least squares approach. Review of Financial Studies 14(1), 113-147.

Marathe, R. and Ryan, S., 2005. On the validity of the geometric brownian motion assumption. Engineering Economist. 50(2), 159-192.

Martzoukos, S., Trigeorgis, L., 2002. Real (investment) options with multiple sources of rare events. European Journal of Operational Research. 136, 696-706.

Miller, L. T., Park, C. S., 2002. Decision making under uncertainty-real options to the rescue? The Engineering Economist 47(2), 105-150.

Myers, S. C.,1984. Finance theory and financial strategy. Interfaces 14(1), 126-137.

Pérez-Arriaga, J. I., Rubio F. J., Puerta, J. F., Arceluz, J., Marin, J., 1995. Marginal Pricing of Transmission Services: An Analysis of Cost Recovery. Power Systems, IEEE Transactions on. 10(1), 546-553, February.

Pringles, R., Olsina, F., Garcés, F., 2007. Real options in evaluating investments in competitive electricity markets - state of the art (in Spanish), XII ERIAC - CIGRÉ, Foz do Iguazú, Brazil, 27-30 May.

Rosellón, J., 2003. Different approaches towards electricity transmission expansion. The Review of Network Economics 2(3), 238-269.

Schwartz, E. S., Trigeorgis, L., 2004. Real options and investment under uncertainty: classical readings and recent contributions. MIT Press, Cambridge, Massachusetts.

Trigeorgis, L., 1996. Real options: managerial flexibility and strategy in resource allocation, MIT Press, Cambridge, Massachusetts.

Vazquez, P., Olsina, F., 2007. Valuing flexibility of DG investments in transmission expansion planning. Power Tech Proceedings, 2007 IEEE Switzerland, 1-6.

Wijnia, Y.C. Herder, P.M., 2005. Options for real options: dealing with uncertainty in investment decisions for electricity networks. IEEE International Conference on Systems, Man and Cybernetics, 4, 3682- 3688.

Wu,F. F., Zheng, F. L., Wen,F. S., 2006 .Transmission investment and expansion planning in a restructured electricity market. Energy 31, 954-966. 


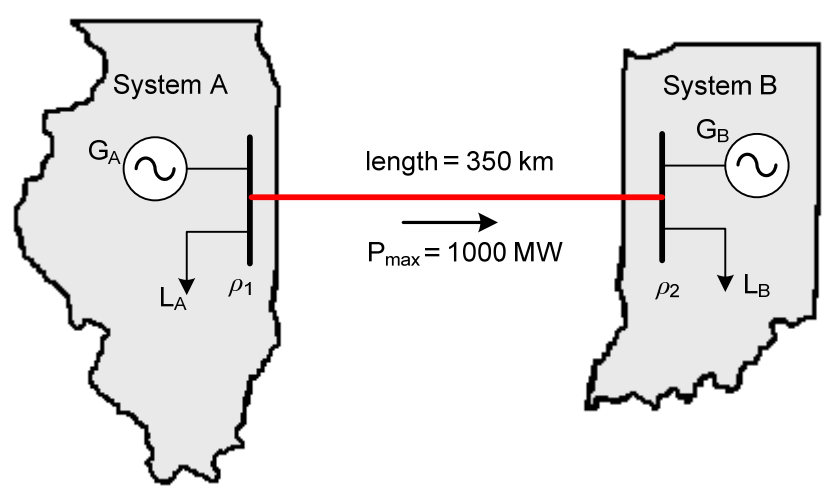

Fig. 1. Electric topology of the example case

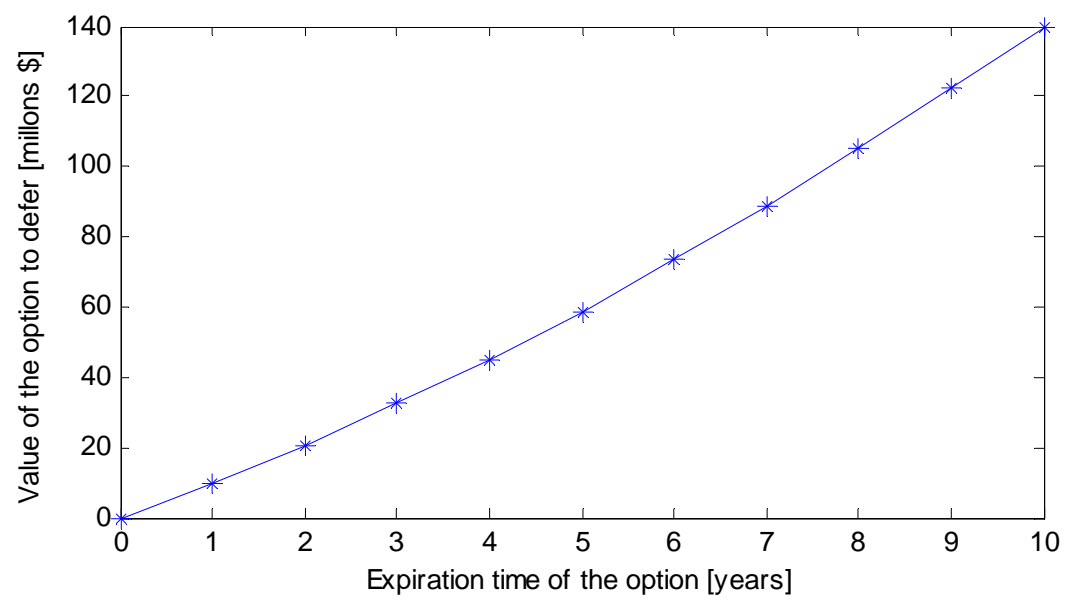

Fig. 2. Monetary value of the option to defer investment decision

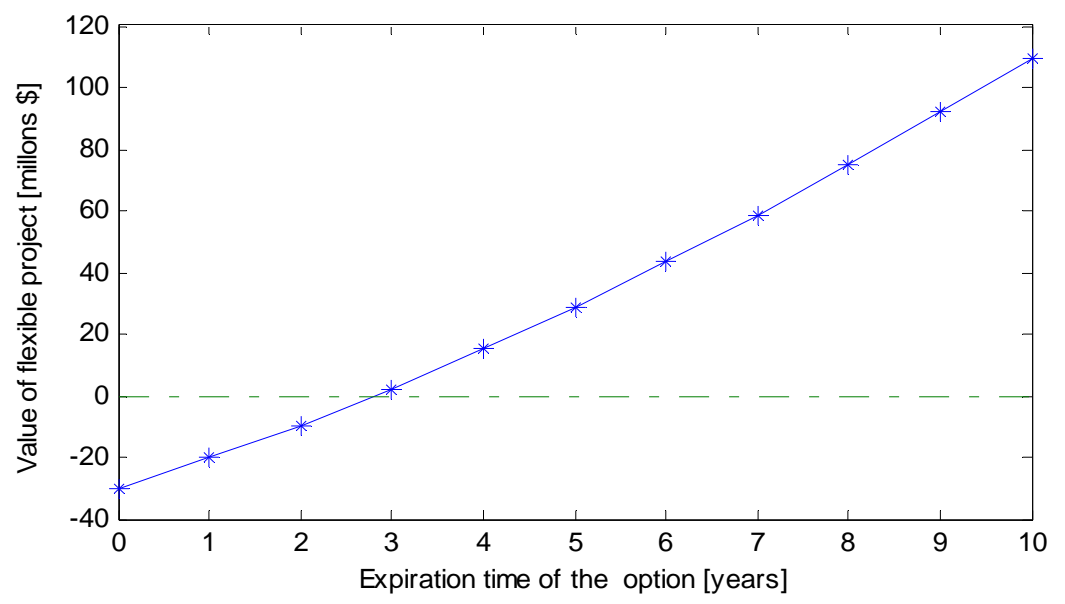

Fig. 3. Expected value of the project considering the option to defer 


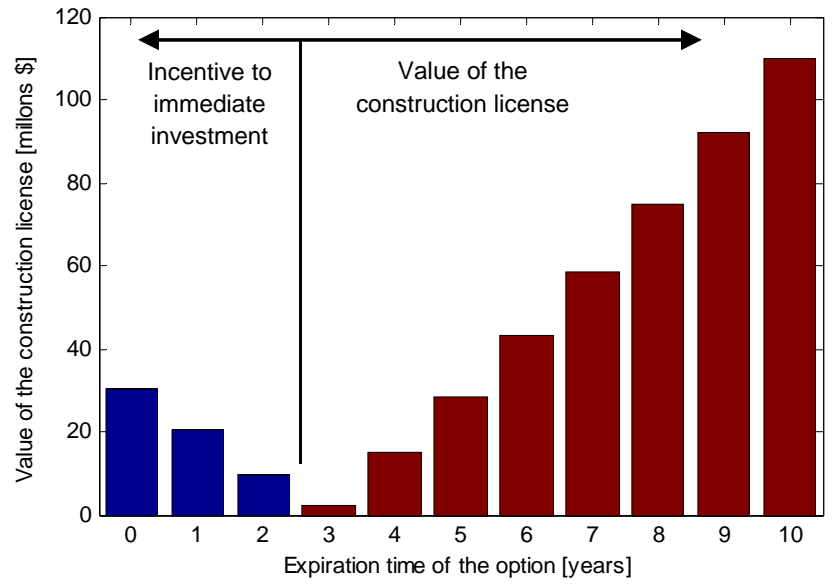

Fig. 4. Value of the construction license

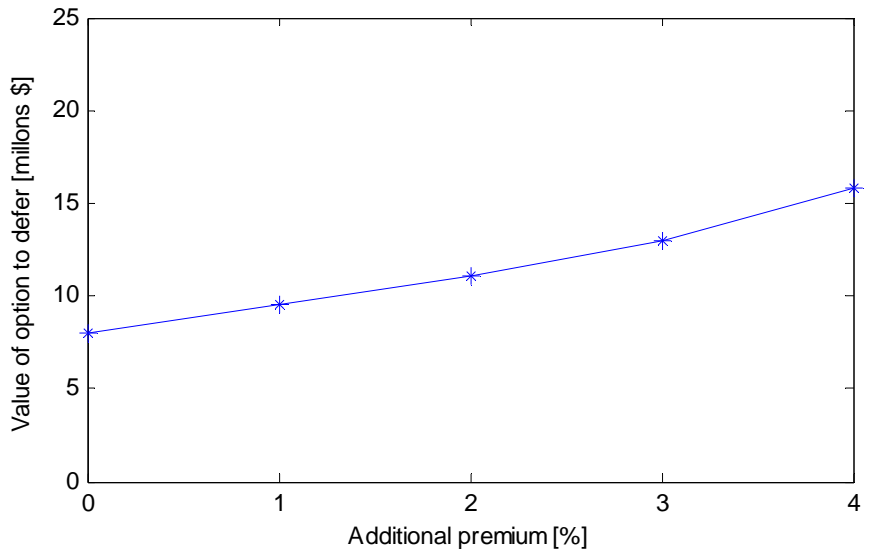

Fig.5. Value of the flexible project with the option to defer

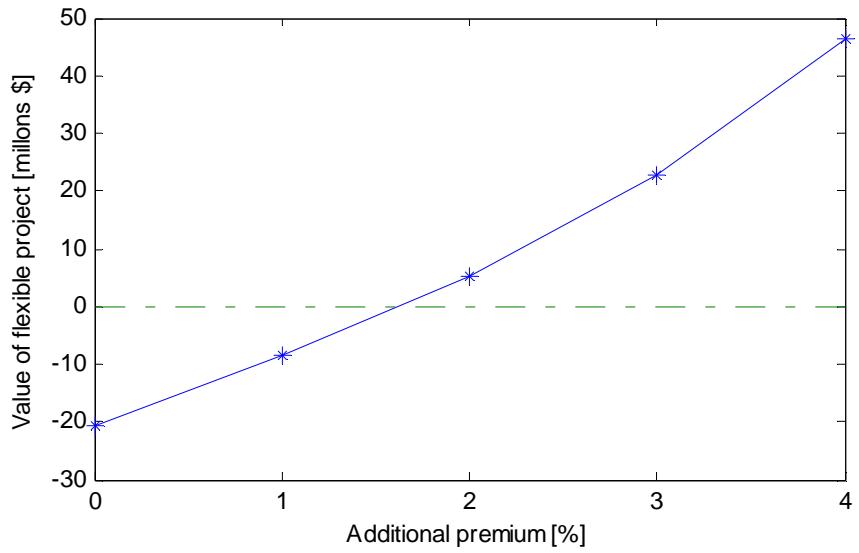

Fig.6. Value of the flexible project with the option to defer 


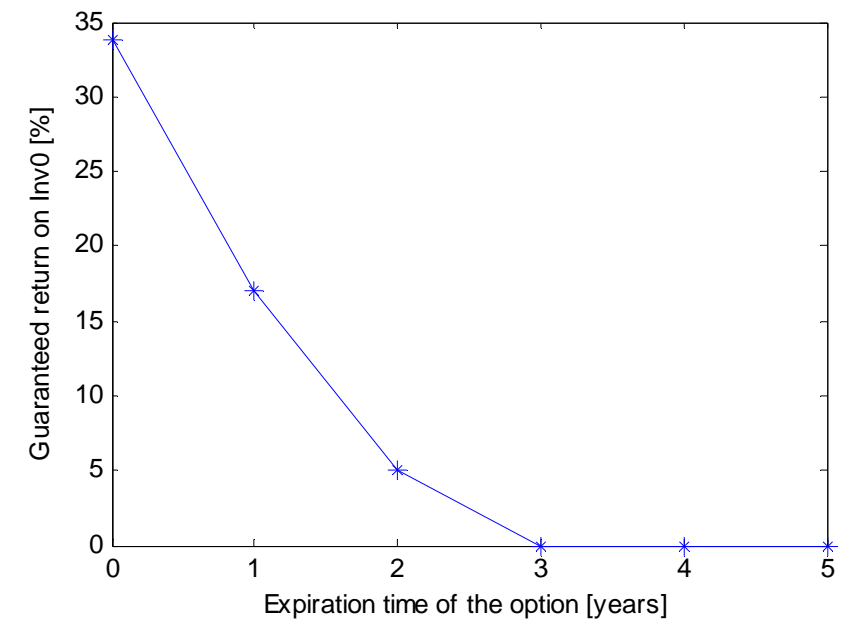

Fig. 7. Guaranteed return on the initial investment that makes the project a profitable investment

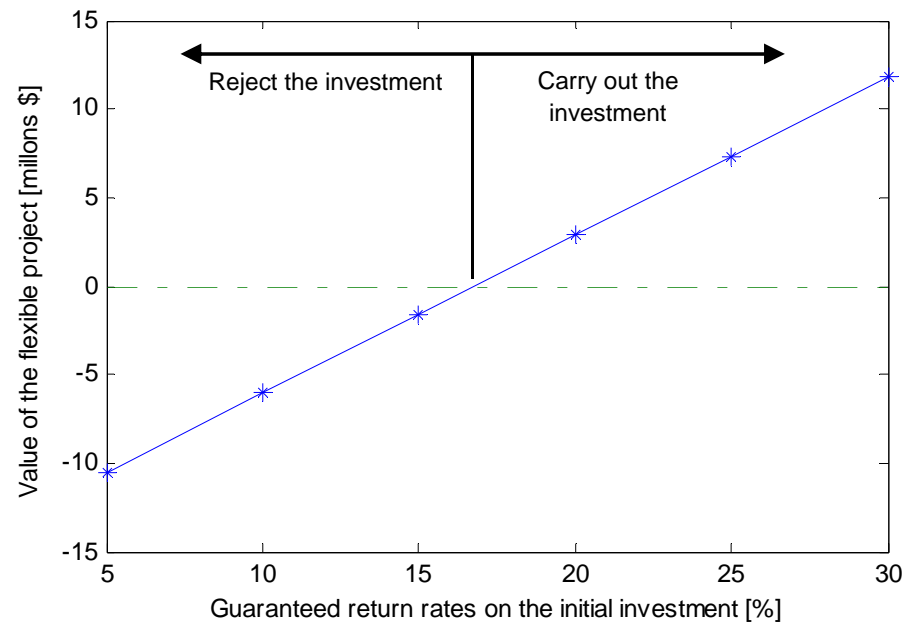

Fig. 8. Value of the flexible project based on the guaranteed return on the investment cost for a one-year license and a price cap of $1000 \$ / M W h$

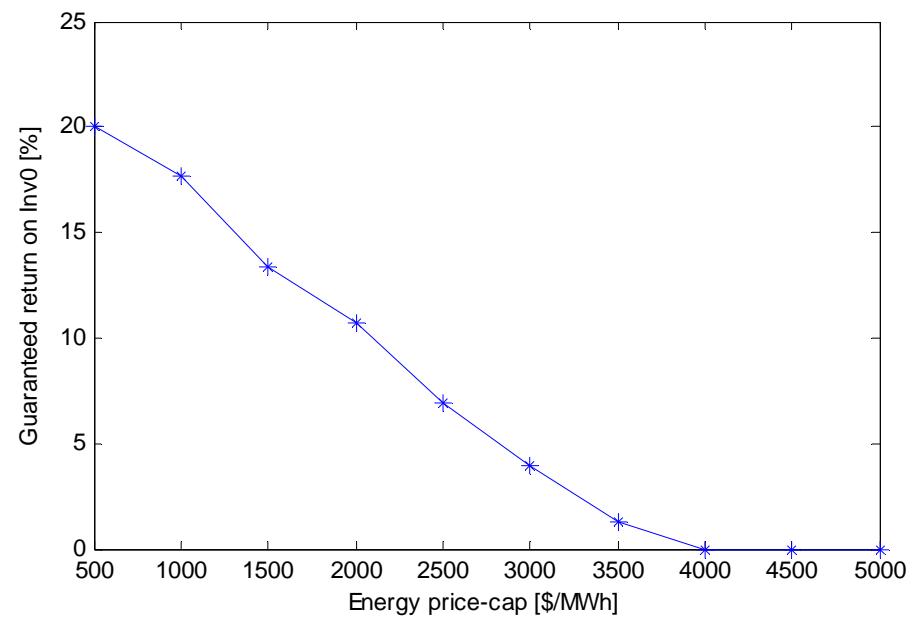

Fig.9. Level of guaranteed return on the investment cost as a function of the price cap for turning the interconnection investment to be economically feasible 
Table I. Electricity demand

\begin{tabular}{cccccccc}
\hline System & \multicolumn{2}{c}{ Demand } & \multicolumn{2}{c}{ Duration } & Correlation & $\begin{array}{c}\text { Growth } \\
\text { rate }\end{array}$ & $\begin{array}{c}\text { Standard } \\
\text { deviation } \\
{[\%]}\end{array}$ \\
& $\begin{array}{c}\text { Peak } \\
{[\mathrm{MW}]}\end{array}$ & $\begin{array}{c}\text { Base } \\
{[\mathrm{MW}]}\end{array}$ & $\begin{array}{c}\text { Peak } \\
{[\mathrm{h}]}\end{array}$ & $\begin{array}{c}\text { Base } \\
{[\mathrm{h}]}\end{array}$ & & {$[\%]$} & {$[\%]$} \\
\hline $\mathrm{A}$ & 900 & 750 & 2190 & 6570 & 0.65 & 2.00 & 2.00 \\
$\mathrm{~B}$ & 1750 & 1350 & 2190 & 6570 & 0.65 & 3.00 & 2.50 \\
\hline
\end{tabular}

Table II. Generation costs parameters

\begin{tabular}{cccccccc}
\hline Generation & $\begin{array}{c}\text { Initial } \\
\text { price } \\
{[\$ / \mathrm{MBTU}]}\end{array}$ & $\begin{array}{c}\text { Long-term } \\
\text { price }\end{array}$ & [\$MBTU] & & Volatility & $\begin{array}{c}\text { Reversion } \\
\text { coefficient }\end{array}$ & \multicolumn{3}{c}{ Input-output function } \\
$\mathrm{a}_{0}$ & $\begin{array}{c}\mathrm{a}_{1} \\
{[\mathrm{MBTU} / \mathrm{h}]}\end{array}$ & {$[\mathrm{MBTU} / \mathrm{MWh}]$} & {$\left[\mathrm{MBTU} / \mathrm{MW}^{2} \mathrm{~h}\right]$} \\
\hline $\mathrm{G}_{\mathrm{A}}$ & 1.70 & 1.465 & 0.12 & 0.30 & 438.43 & 8.191 & 0.00644 \\
$\mathrm{G}_{\mathrm{B}}$ & 2.115 & 1.750 & 0.12 & 0.30 & 285.40 & 8 & 0.00733 \\
\hline
\end{tabular}

Table III. Reliability parameters of system components

\begin{tabular}{ccccc}
\hline Component & $\begin{array}{c}\text { Capacity } \\
{[\mathrm{MW}]}\end{array}$ & $\begin{array}{c}\boldsymbol{\mu} \\
{\left[\mathrm{h}^{-1}\right]}\end{array}$ & $\begin{array}{c}\boldsymbol{P} \mathbf{H}(\mathbf{F}) \\
{\left[\mathrm{h}^{-1}\right]}\end{array}$ & \\
\hline Generator A & 5000 & 0.000001 & 0.495 & 0.00000202 \\
Generator B & 5000 & 0.000001 & 0.190 & 0.00000111 \\
Line & 1000 & 0.005 & 0.0495 & 0.0917 \\
\hline
\end{tabular}

